\title{
PENGARUH VARIASI TEMPERATUR TERHADAP MORFOLOGI BERBAGAI LAPISAN KOMPOSIT : SEBUAH KAJIAN
}

\author{
Melati Sandra ${ }^{a}$, Esmar Budi ${ }^{\mathrm{b}}$, Hadi Nasbey ${ }^{\mathrm{c}}$ \\ Program Studi Fisika FMIPA, Universitas Negeri Jakarta, Jl. Rawamangun Muka I, Jakarta 13220, Indonesia \\ Email: ${ }^{a}$ melatisandraa@gmail.com, b)esmarbudi@unj.ac.id, ${ }^{c}$ hadinasbey@unj.ac.id
}

\begin{abstract}
Abstrak
Material keras seperti logam banyak dimanfaatkan dalam kehidupan sehari-hari. Meski pada praktiknya, logam memiliki kelemahan seperti rentan mengalami korosi dan aus. Salah satu cara yang dapat digunakan untuk meningkatkan ketahanan logam adalah dengan pembentukan lapisan komposit. Salah satu teknik pelapisan yang relatif mudah, murah, dan cepat adalah elektrodeposisi. Pelapisan menggunakan komposit dengan nikel sebagai matriks dan senyawa nitrida, hidroksida, dan oksida sebagai penguat banyak digunakan karena dapat diaplikasikan sebagai perlindungan aus serta korosi. Salah satu paramater yang sangat berpengaruh dalam proses pelapisan ialah temperatur. Hal ini dibuktikan dengan hasil karakterisasi yang menunjukkan bahwa kenaikan temperatur mempengaruhi hasil morfologi dari masing-masing lapisan komposit seperti ukuran dan orientasi butir. Sehingga, perlu diketahui temperatur optimum untuk mendapatkan morfologi lapisan komposit yang baik.
\end{abstract}

Kata-kata kunci: lapisan komposit, elektrodeposisi, temperatur.

\begin{abstract}
Hard materials such as metal are widely used in daily life. Although in practice, metals have weaknesses such as being susceptible to corrosion and wear. One way that can be used to increase metal resistance is by developing or forming composite coating. One relatively easy, inexpensive and fast coating technique is electrodeposition. Coatings using composites with nickel as a matrix and nitride, hydroxide and cheerful compounds as reinforcement are widely used because they can be applied as a protection against wear and corrosion. One of the most influential parameters in the coating process is temperature. This is evidenced by the results of the characterization which show that the temperature rise affects the morphological results of each composite layer such as grain size and orientation. Thus, it is necessary to know the optimum temperature to obtain a good morphology of the composite coating.
\end{abstract}

Keywords: the composite coating, electrodeposition, temperature.

\section{PENDAHULUAN}

Material keras seperti logam banyak dimanfaatkan dalam kehidupan sehari-hari. Meski pada praktiknya, logam memiliki kelemahan seperti rentan mengalami korosi dan aus. Salah satu cara yang dapat digunakan untuk meningkatkan ketahanan logam adalah dengan pembentukan lapisan komposit untuk membuat lapisan keras sebagai bahan pelindung [1], [2]. Salah satu teknik pelapisan 
yang relatif mudah, murah dan cepat adalah dengan melakukan proses pengendapan logam menggunakan prinsip elektrolisa yang disebut elektrodeposisi [3]. Untuk menggunakan teknik ini, dua elektroda yang berfungsi sebagai substrat/katoda dan elektroda pembanding diperlukan. Tak jarang ada tambahan satu elektroda lainnya yang berfungsi sebagai counter atau pembantu sehingga menggunakan tiga elektroda [4].

Temperatur merupakan salah satu parameter penting yang menentukan lapisan morfologi [5]. Pada proses elektrodeposisi, peningkatan temperatur dapat mempengaruhi ukuran dan orientasi butir [6]. Meningkatnya temperatur menyebabkan peningkatan ketebalan lapisan. Ini terjadi karena semakin meningkatnya temperatur mengakibatkan peningkatan energi yang akan mempercepat pelepasan ion elektron. Kondisi ini semakin mempercepat gerakan elektron dari anoda ke katoda sehingga yang mengendap di permukaan bahan semakin bertambah dan menghasilkan morfologi yang berbeda-beda pada setiap permukaan lapisan.

Tulisan ini merupakan kajian awal dari hasil pengujian beberapa lapisan komposit dengan matriks nikel untuk mengetahui morfologi dari permukaan lapisan komposit. Pengaruh parameter proses seperti variasi temperatur saat melakukan proses elektrodeposisi dan temperatur optimum setiap lapisan komposit akan diselidiki.

\section{LAPISAN KOMPOSIT}

Lapisan adalah sebuah pelindung yang dapat diaplikasikan ke permukaan dari sebuah substrat [7]. Sedangkan, material komposit merupakan kombinasi dua atau lebih material yang berbeda, dengan syarat adanya ikatan antara kedua material tersebut [8]. Bahan komposit biasanya dibangun dari dua fase, yaitu fase matriks dan fase dispersi (penguat) [9]. Pelapisan menggunakan komposit biasanya dapat memberikan berbagai macam sifat, seperti ketahanan aus, perlindungan korosi temperatur tinggi, ketahanan oksidasi pada permukaan material [10].

Nikel ialah salah satu material yang digunakan sebagai matriks lapisan komposit [11]. Kemudian data juga menunjukkan bahwa proses pelapisan nikel ditunjukan untuk keperluan utama sebagai perlindungan korosi sebesar 30\% dan perlindungan aus sebesar 25\% [12]. Berbagai senyawa seperti partikel nitrida, hidroksida, maupun oksida dipakai sebagai penguat pada lapisan komposit. Hal ini bertujuan untuk meningkatkan sifat, karakteristik, dan kemampuan kerja khususnya meningkatkan kehalusan morfologi permukaan lapisan komposit [13].

TABEL 1. Hasil kajian pengaruh suhu terhadap morfologi lapisan komposit

\begin{tabular}{ccccc}
\hline Penelitian & Tahun & Lapisan Komposit & Temperatur & Pengujian \\
\hline$[5]$ & 2019 & $\mathrm{Ni}(\mathrm{OH})_{2}$ & $5,10,15,20,25$ & SEM \\
{$[2]$} & 2019 & $\mathrm{Ni}-\mathrm{TiAlN} / \mathrm{Si}_{3} \mathrm{~N}_{4}$ & $35,40,45$ & SEM \\
{$[1],[13]$} & 2019, & $\mathrm{Ni}-\mathrm{TiN} / \mathrm{Si}_{3} \mathrm{~N}_{4}$ & $35,40,45$ & SEM \\
& 2020 & & & \\
{$[14]$} & 2011 & $\mathrm{Ni}-\mathrm{TiN}$ & $30,40,50,60$ & SEM \\
{$[15]$} & 2011 & $\mathrm{Ni}-\mathrm{CeO}_{2}$ & $35,40,45,50,55$ & FESEM \\
{$[16]$} & 2012 & $\mathrm{Ni}(\mathrm{OH})_{2}$ & $10,20,30,40$ & FESEM \\
\hline
\end{tabular}

\section{PEMBAHASAN}

Hasil dari beberapa kajian menunjukan terdapat beberapa variasi hasil lapisan morfologi terhadap kenaikan temperatur. Berdasarkan 6 lapisan komposit dari beberapa penelitian telah digunakan lapisan komposit : $\mathrm{Ni}(\mathrm{OH})_{2}, \mathrm{Ni}-\mathrm{TiAlN} / \mathrm{Si}_{3} \mathrm{~N}_{4}, \mathrm{Ni}-\mathrm{TiN} / \mathrm{Si}_{3} \mathrm{~N}_{4}, \mathrm{Ni}-\mathrm{TiN}$, dan $\mathrm{Ni}-\mathrm{CeO}_{2}$.

TABEL 2. Hasil morfologi berbagai lapisan komposit terhadap temperatur

\begin{tabular}{|c|c|c|c|c|c|c|}
\hline $\begin{array}{l}\text { Temp- } \\
\text { eratur } \\
\text { (C) }\end{array}$ & $\mathrm{Ni}(\mathrm{OH})_{2}[5]$ & $\begin{array}{l}\mathrm{Ni}-\mathrm{TiAlN} / \mathrm{Si}_{3} \mathrm{~N}_{4} \\
{[2]}\end{array}$ & $\begin{array}{l}\mathrm{Ni}-\mathrm{TiN} / \mathrm{Si}_{3} \mathrm{~N}_{4}[1], \\
{[14]}\end{array}$ & Ni-TiN [15] & $\mathrm{Ni}-\mathrm{CeO}_{2}[16]$ & $\mathrm{Ni}(\mathrm{OH})_{2}[17]$ \\
\hline 10 & $\begin{array}{l}\text { Banyak grains } \\
\text { ditemukan dan } \\
\text { ukuran partikel } \\
\text { tidak } \\
\text { mengalami } \\
\text { peningkatan }\end{array}$ & & & & & $\begin{array}{l}\text { Lapisan relatif } \\
\text { padat, rata, dan } \\
\text { halus }\end{array}$ \\
\hline
\end{tabular}




\begin{tabular}{|c|c|c|c|c|c|c|}
\hline $\begin{array}{l}\text { Temp- } \\
\text { eratur } \\
\text { (C) }\end{array}$ & $\mathrm{Ni}(\mathrm{OH})_{2}[5]$ & $\begin{array}{l}\mathrm{Ni}-\mathrm{TiAlN} / \mathrm{Si}_{3} \mathrm{~N}_{4} \\
{[2]}\end{array}$ & $\begin{array}{l}\mathrm{Ni}-\mathrm{TiN} / \mathrm{Si}_{3} \mathrm{~N}_{4}[1], \\
{[14]}\end{array}$ & Ni-TiN [15] & $\mathrm{Ni}-\mathrm{CeO}_{2}[16]$ & $\mathrm{Ni}(\mathrm{OH})_{2}[17]$ \\
\hline & ukuran & & & & & \\
\hline 15 & $\begin{array}{l}\text { Ditemukan grain } \\
\text { yang lebih besar }\end{array}$ & & & & & \\
\hline 20 & $\begin{array}{l}\text { Ditemukan grain } \\
\text { yang lebih besar } \\
\text { dibanding } \\
\text { temperatur } \\
\text { sebelumnya }\end{array}$ & & & & & $\begin{array}{l}\text { Lapisan } \\
\text { permukaan } \\
\text { menjadi sangat } \\
\text { berpori. }\end{array}$ \\
\hline 25 & $\begin{array}{l}\text { retakan dan } \\
\text { lapisan } \\
\text { permukaan } \\
\text { terlihat seperti } \\
\text { ditutupi jarum- } \\
\text { jarum kecil. }\end{array}$ & & & & & \\
\hline 35 & & $\begin{array}{l}\text { Morfologi } \\
\text { permukaan } \\
\text { lapisan yang } \\
\text { dihasilkan } \\
\text { relatif berpori. } \\
\text { Adanya pori } \\
\text { disebabkan } \\
\text { lapisan di atas } \\
\text { permukaan } \\
\text { substrat tidak } \\
\text { merata } \\
\text { dengan sempurna }\end{array}$ & $\begin{array}{l}\text { cenderung berpori } \\
\text { dan terdapat } \\
\text { aglomerat } \\
\text { berukuran kecil } \\
\text { hampir di seluruh } \\
\text { permukaan }\end{array}$ & & & \\
\hline 40 & & $\begin{array}{l}\text { lapisan yang } \\
\text { lebih baik } \\
\text { karena sedikit } \\
\text { berpori dan } \\
\text { aglomerat yang } \\
\text { terbentuk lebih } \\
\text { sedikit. } \\
\text { Hal ini terjadi } \\
\text { karena gerakan } \\
\text { molekul dalam } \\
\text { larutan semakin } \\
\text { cepat dan } \\
\text { kekentalan } \\
\text { larutan } \\
\text { menurun } \\
\text { sehingga } \\
\text { meningkatkan } \\
\text { stabilitas dan } \\
\text { dispersi partikel } \\
\text { pada larutan } \\
\text { sehingga } \\
\text { membuat } \\
\text { ukuran butir } \\
\text { menjadi } \\
\text { lebih halus. }\end{array}$ & $\begin{array}{l}\text { Morfologi } \\
\text { permukaan } \\
\text { lapisan sedikit } \\
\text { berpori dan } \\
\text { aglomerat yang } \\
\text { terbentuk lebih } \\
\text { sedikit } \\
\text { dibandingkan } \\
\text { pada saat } \\
\text { temperatur } 35^{\circ} \mathrm{C} \text {. }\end{array}$ & $\begin{array}{l}\text { Perpindahan } \\
\text { molekul di dalam } \\
\text { larutan terjadi } \\
\text { dengan cepat dan } \\
\text { viskositas larutan } \\
\text { menurun } \\
\text { mengakibatkan } \\
\text { stabilitas dan } \\
\text { dispersi dari } \\
\text { larutan elektrolit } \\
\text { menjadi meningkat }\end{array}$ & & $\begin{array}{l}\text { Pori permukaan } \\
\text { semakin } \\
\text { meluas dan } \\
\text { menebal. }\end{array}$ \\
\hline 45 & & $\begin{array}{l}\text { Banyaknya atom } \\
\text { hidrogen yang } \\
\text { dihasilkan selama } \\
\text { elektrodeposisi } \\
\text { menyebabkan } \\
\text { absorpsi partikel } \\
\text { pada permukaan } \\
\text { katoda terhambat } \\
\text { sehingga ukuran } \\
\text { butir menjadi } \\
\text { kasar. }\end{array}$ & $\begin{array}{l}\text { Morfologi lapisan } \\
\text { yang terbentuk } \\
\text { permukaannya } \\
\text { kasar dan } \\
\text { aglomerat } \\
\text { tersebar hampir di } \\
\text { seluruh } \\
\text { permukaan } \\
\text { lapisan. }\end{array}$ & & $\begin{array}{l}\text { Endapan dari } \\
\text { partikel } \mathrm{CeO}_{2} \\
\text { meningkat, } \\
\text { ukuran kristal } \\
\text { dari nikel atau } \\
\text { Ni menurun, } \\
\text { dan hasil SEM } \\
\text { menjelaskan } \\
\text { bahwa terjadi } \\
\text { jumlah } \\
\text { maksimum } \\
\text { dari } \mathrm{CeO}_{2} \\
\text { yang } \\
\text { bergabung } \\
\text { dengan sebuah } \\
\text { distribusi yang } \\
\text { seragam di } \\
\text { dalam } \\
\text { matriks nikel } \\
\end{array}$ & \\
\hline
\end{tabular}




\begin{tabular}{|c|c|c|c|c|c|c|}
\hline $\begin{array}{l}\text { Temp-- } \\
\text { eratur } \\
\text { (C) }\end{array}$ & $\mathrm{Ni}(\mathrm{OH})_{2}[5]$ & $\begin{array}{l}\mathrm{Ni}-\mathrm{TiAlN} / \mathrm{Si}_{3} \mathrm{~N}_{4} \\
{[2]}\end{array}$ & $\begin{array}{l}\mathrm{Ni}-\mathrm{TiN}_{/} \mathrm{Si}_{3} \mathrm{~N}_{4}[1], \\
{[14]}\end{array}$ & Ni-TiN [15] & $\mathrm{Ni}-\mathrm{CeO}_{2}[16]$ & $\mathrm{Ni}(\mathrm{OH})_{2}[17]$ \\
\hline 50 & & & & & \multirow[b]{2}{*}{$\begin{array}{l}\text { terjadi } \\
\text { penurunan } \\
\text { jumlah dari } \\
\text { endapan } \\
\mathrm{CeO} 2 \\
\text { partikel dalam } \\
\text { matriks nikel } \\
\text { dan maka } \\
\text { ukuran kristal } \\
\text { dari nikel } \\
\text { meningkat } \\
\text { kembali. }\end{array}$} & \\
\hline 55 & & & & & & \\
\hline 60 & & & & $\begin{array}{l}\text { Tegangan antar } \\
\text { muka menurun di } \\
\text { antara komposit } \\
\text { Ni- TiN dan } \\
\text { gelembung } \mathrm{H}_{2} \\
\text { yang dihasilkan } \\
\text { selama proses } \\
\text { elektrodeposisi, } \\
\text { sehingga } \\
\text { mempercepat } \\
\text { tingkat penurunan } \\
\text { dari gelembung } \mathrm{H}_{2} \\
\text { pada katoda dan } \\
\text { mempercepat } \\
\text { penyerapan } \\
\text { kembali } \\
\text { nanopartikel TiN } \\
\text { dari permukaan } \\
\text { katoda. }\end{array}$ & & \\
\hline 70 & & & & $\begin{array}{l}\text { Stabilitas dari } \\
\text { larutan } \\
\text { elektrolit } \\
\text { menurun } \\
\text { dikarenakan } \\
\text { penguapan air } \\
\text { yang cepat, } \\
\text { serta proses } \\
\text { elektrodeposisi } \\
\text { menjadi sulit } \\
\text { dan } \\
\text { menurunkan } \\
\text { kualitas } \\
\text { komposit }\end{array}$ & & \\
\hline
\end{tabular}

Berdasarkan hasil morfologi berbagai lapisan komposit $\mathrm{Ni}(\mathrm{OH})_{2}$ pada tabel diatas [5] dan [17], dapat dilihat pada saat temperatur $10 \mathrm{C}$, ditemukan banyak grain, ukuran partikel tidak meningkat, serta lapisan relatif padat, rata, dan halus. Pada temperatur $15 \mathrm{C}$, ditemukan grain yang lebih besar. Pada temperatur $20 \mathrm{C}$ dan $25 \mathrm{C}$, diitemukan grain yang lebih besar dibanding temperatur sebelumnya, retakan dan lapisan permukaan terlihat seperti ditutupi jarum-jarum kecil serta lapisan permukaan menjadi berpori. Pada temperatur $35 \mathrm{C}$ dan $40 \mathrm{C}$, ditemukan pori permukaan semakin meluas dan menebal. Sehingga dilihat dari hasil morfologinya, temperatur optimum untuk pembentukan lapisan komposit $\mathrm{Ni}(\mathrm{OH})_{2}$ ialah pada temperatur $10 \mathrm{C}-15 \mathrm{C}$ karena lapisan relatif halus, sedikit berpori, dan grain yang kecil.

Berdasarkan hasil morfologi berbagai lapisan komposit Ni-TiAlN/Si $3 \mathrm{~N}_{4}[2], \mathrm{Ni}-\mathrm{TiN} / \mathrm{Si}_{3} \mathrm{~N}_{4}$ [1], [14], dan Ni-TiN [15], dapat dilihat pada saat temperatur $35 \mathrm{C}$, morfologi permukaan lapisan $\mathrm{Ni}$ TiAlN/ $\mathrm{Si}_{3} \mathrm{~N}_{4}$ [2] yang dihasilkan relatif berpori dan adanya pori disebabkan lapisan di atas permukaan substrat tidak merata dengan sempurna, sedangkan untuk morfologi permukaan lapisan $\mathrm{Ni}-\mathrm{TiN} / \mathrm{Si}_{3} \mathrm{~N}_{4}$ [1], [14] cenderung berpori dan terdapat aglomerat berukuran kecil hampir di seluruh permukaan. Pada temperatur $40 \mathrm{C}$, morfologi lapisan Ni-TiAlN/Si $\mathrm{N}_{4}[2]$ menjadi lebih baik karena sedikit berpori dan aglomerat yang terbentuk lebih sedikit, hal ini terjadi karena gerakan molekul dalam larutan semakin cepat dan kekentalan larutan menurun sehingga meningkatkan stabilitas dan 
dispersi partikel pada larutan sehingga membuat ukuran butir menjadi lebih halus, sedangkan pada morfologi lapisan $\mathrm{Ni}-\mathrm{TiN} / \mathrm{Si}_{3} \mathrm{~N}_{4}$ [1], [14] terlihat sedikit berpori dan aglomerat yang terbentuk lebih sedikit dibandingkan pada saat temperatur $35^{\circ} \mathrm{C}$. Pada temperatur $45 \mathrm{C}$, morfologi lapisan $\mathrm{Ni}$ TiAlN/Si ${ }_{3} \mathrm{~N}_{4}[2]$ terlihat banyak atom hidrogen yang dihasilkan selama elektrodeposisi menyebabkan absorpsi partikel pada permukaan katoda terhambat sehingga ukuran butir menjadi kasar, sedangkan morfologi lapisan $\mathrm{Ni}-\mathrm{TiN} / \mathrm{Si}_{3} \mathrm{~N}_{4}$ [1], [14] terlihat permukaannya kasar dan aglomerat tersebar hampir di seluruh permukaan lapisan. Hasil morfologi lapisan Ni-TiN [15] menunjukkan bahwa saat temperatur $35 \mathrm{C}-45 \mathrm{C}$, perpindahan molekul di dalam larutan terjadi dengan cepat dan viskositas larutan menurun mengakibatkan stabilitas dan dispersi dari larutan elektrolit menjadi meningkat, sedangkan pada saat temperatur $60 \mathrm{C}$, tegangan antar muka menurun di antara komposit Ni-TiN dan gelembung $\mathrm{H}_{2}$ yang dihasilkan selama proses elektrodeposisi, sehingga mempercepat tingkat penurunan dari gelembung $\mathrm{H}_{2}$ pada katoda dan mempercepat penyerapan kembali nanopartikel TiN dari permukaan katoda, namun pada temperatur $70 \mathrm{C}$, stabilitas dari larutan elektrolit menurun dikarenakan penguapan air yang cepat, serta proses elektrodeposisi menjadi sulit dan menurunkan kualitas komposit. Sehingga dilihat dari hasil morfologi lapisan komposit dengan matriks nikel dan dengan partikel penguat nitrida, didapatkan temperatur optimum yaitu pada rentang $35 \mathrm{C}-60 \mathrm{C}$, hal ini dikarenakan semakin besar temperatur maka semakin sedikit pori sehingga lapisan menjadi semakin halus, semakin sedikit aglomerat, dan terdapat banyak komponen partikel nitrida yang menempel pada katoda sehingga menyebabkan permukaan lapisan komposit menjadi semakin halus. Namun, pada suhu $45 \mathrm{C}$, hasil morfologi lapisan komposit menunjukkan bahwa permukaan lapisan komposit dan ukuran butir menjadi kasar karena banyak atom hidrogen yang dihasilkan selama elektrodeposisi menyebabkan absopsi partikel pada pemukaan katoda terhambat. Sedangkan pada saat temperatur $70 \mathrm{C}$ atau melewati batas optimum akan menyebabkan stabilitas dari larutan elektrolit menurun dikarenakan penguapan air yang cepat.

Berdasarkan hasil morfologi lapisan komposit $\mathrm{Ni}-\mathrm{CeO}_{2}[16]$, pada temperatur $45 \mathrm{C}$ terlihat bahwa endapan dari partikel $\mathrm{CeO}_{2}$ meningkat, ukuran kristal dari nikel menurun, dan hasil SEM menjelaskan bahwa terjadi jumlah maksimum dari $\mathrm{CeO}_{2}$ yang bergabung dengan sebuah distribusi yang seragam di dalam matriks nikel. Pada temperatur $50 \mathrm{C}-55 \mathrm{C}$ terjadi penurunan jumlah dari endapan $\mathrm{CeO}_{2}$ partikel dalam matriks nikel dan maka ukuran kristal dari nikel meningkat kembali. Sehingga dilihat dari hasil morfologi lapisan komposit $\mathrm{Ni}-\mathrm{CeO}_{2}$, didapatkan temperatur optimum yaitu pada $45 \mathrm{C}$ karena endapan dari partikel $\mathrm{CeO}_{2}$ meningkat dan ukuran kristal dari nikel menurun menyebabkan permukaan lapisan menjadi halus.

Penjelasan diatas menunjukkan bahwa kandungan partikel penguat yang berbeda pada setiap lapisan komposit akan menghasilkan morfologi yang berbeda pula pada setiap temperatur dan kenaikan temperatur juga sangat mempengaruhi hasil morfologi dari masing-masing lapisan komposit.

Hasil morfologi lapisan komposit yang baik adalah permukaan komposit yang sangat halus, seragam, kompak, dengan ukuran partikel yang kecil, tidak ada retakan yang disebabkan oleh adanya stress [18]. Untuk mendapatkan hasil morfologi yang baik maka seiring meningkatnya temperatur harus terdapat banyak endapan penguat pada komposit dan terjadi penurunan jumlah endapan matriks pada komposit yang menyebabkan ukuran grain dari endapan menurun dan grain menjadi halus, dan sedikit terjadi penyerapan hidrogen dan penurunan tegangan/stress karena jika banyak atom hidrogen yang dihasilkan selama elektrodeposisi menyebabkan absorpsi partikel pada permukaan katoda terhambat sehingga ukuran butir menjadi kasar [2]. Gerakan molekul dalam larutan semakin cepat dan kekentalan larutan menurun seiringi meningkatnya temperatur sehingga ukuran butir menjadi lebih halus [7].

\section{KESIMPULAN}

Kandungan partikel penguat seperti senyawa nitrida, hidroksida, dan oksida pada setiap lapisan komposit dengan matriks nikel akan mengakibatkan hasil morfologi yang berbeda-beda dan pengaruh kenaikan temperatur juga sangat mempengaruhi hasil morfologi dari masing-masing lapisan komposit. Temperatur larutan elektrolit yang optimum dipakai dalam proses elektrodeposisi 
untuk menghasilkan morfologi permukaan lapisan komposit yang baik yaitu temperatur $10 \mathrm{C}-15 \mathrm{C}$ untuk lapisan komposit $\mathrm{Ni}(\mathrm{OH})_{2}$, temperature $35 \mathrm{C}-60 \mathrm{C}$ untuk lapisan komposit Ni-TiAlN/Si ${ }_{3} \mathrm{~N}_{4}$, $\mathrm{Ni}-\mathrm{TiN} / \mathrm{Si}_{3} \mathrm{~N}_{4}$ dan $\mathrm{Ni}-\mathrm{TiN}$, serta temperature $45 \mathrm{C}$ untuk lapisan komposit $\mathrm{Ni}-\mathrm{CeO}_{2}$.

\section{REFERENSI}

[1] L. Kusumawati, E. Budi and I. Sugihartono, "Pengaruh Temperatur Terhadap Pembentukan Lapisan Komposit Ni-Tin/Si3n4 Dengan Menggunakan Metode Elektrodeposisi," Pros. Semin. Nas. Fis. SNF2019, vol. VIII, pp. SNF2019-PA-27-32, 2019, doi: 10.21009/03.snf2019.02.pa.05.

[2] A. W. Andiani, E. Budi and I. Sugihartono, "Pembentukan Lapisan Komposit NiTialn/Si3n4 Menggunakan Metode Elektrodeposisi Dengan Variasi Temperatur," Pros. Semin. Nas. Fis. SNF2019, vol. VIII, pp. 145-148, 2019.

[3] S. Marwati, "Pengaruh Agen Pereduksi Dalam Proses Elektrodeposisi Terhadap Kualitas Deposit Cu dan Ag," Pros. Semin. Nas. Penelitian, Pendidik. dan Penerapan MIPA, pp. 1-8, 2013.

[4] E. Budi, "Potensi Pembentukan Lapisan Super Dan Ultra Keras Senyawa Komposit Nitrida Menggunakan Kaidah Elektrodeposisi," Spektra J. Fis. dan Apl, vol. 1, no. 2, pp. 187-194, 2016, doi: 10.21009/spektra.012.14.

[5] L. Aguilera et al., "Influence of electrodeposition temperature in the electrochemical properties of $\mathrm{Ni}(\mathrm{OH}) 2$ : An experimental and theoretical study," Thin Solid Films, vol. 670, pp. 24-33, 2019, doi: 10.1016/j.tsf.2018.12.007.

[6] L. Jinlong, L. Tongxiang and W. Chen, "Investigation of hydrogen evolution activity for the nickel, nickel-molybdenum nickel-graphite composite and nickel-reduced graphene oxide composite coatings," Appl. Surf. Sci, vol. 366, pp. 353-358, 2016, doi: 10.1016/j.apsusc.2016.01.114.

[7] S. Kumar, S. Pande and P. Verma, "Factor Effecting Electro-Deposition Process," Int. J. Curr. Eng. Technol, vol. 5, no. 2, pp. 700-703, 2015.

[8] M. Zainuri et al., "Pengaruh Pelapisan Permukaan Partikel SiC dengan Oksida Metal Terhadap Modulus Elastisitas Komposit Al / SiC," Makara, Sci, vol. 12, no. 2, pp. 126-133, 2008.

[9] S. Salam, "Studi Sifat Fisis dan Mekanis Komposit Matriks Resin Epoxy yang Diperkuat dengan Serbuk Titania (TiO20)," 2007.

[10] M. R. Vaezi, S. K. Sadrnezhaad and L. Nikzad, "Electrodeposition of Ni-SiC nanocomposite coatings and evaluation of wear and corrosion resistance and electroplating characteristics," Colloids Surfaces A Physicochem. Eng. Asp, vol. 315, no. 1-3, pp. 176-182, 2008, doi: 10.1016/j.colsurfa.2007.07.027.

[11] D. kumar Singh, "Electrocodeposition and Characterization of Ni-WC Composite Coating From Non - Aqueous Bath,” Int. J. Mater. Sci. Appl, vol. 2, no. 2, p. 68, 2013, doi: 10.11648/j.ijmsa.20130202.16.

[12] E. B. and I. S. Muarief, "Sintesis Lapisan Tipis Komposit Ni-TiAlN Menggunakan Teknik Elektrodeposisi pada Berbagai Substrat,” Pros. Semin. Nas. Fis, vol. IV, pp. 81-84, 2015.

[13] S. A. Budi et al., "KOMPOSISI DAN MORFOLOGI PERMUKAAN LAPISAN KOMPOSIT Ni-TiAIN ELEKTRODEPOSISI,” Pros. Bid. Fis, pp. 348-353, 2015.

[14] E. Budi et al., "Effect of Temperature on Electrodeposited Nickel Nitride Composite Coatings," J. Phys. Conf. Ser, vol. 1428, no. 1, 2020, doi: 10.1088/17426596/1428/1/012015. 
[15] X. B. Zhu et al., "Electrodeposition and corrosion behavior of nanostructured Ni-TiN composite films," Trans. Nonferrous Met. Soc. China (English Ed), vol. 21, no. 10, pp. 22162224, 2011, doi: 10.1016/S1003-6326(11)60998-9.

[16] R. Sen, S. Das and K. Das, "The effect of bath temperature on the crystallite size and microstructure of $\mathrm{Ni}-\mathrm{CeO} 2$ nanocomposite coating," Mater. Charact, vol. 62, no. 3, pp. 257262, 2011, doi: 10.1016/j.matchar.2011.01.013.

[17] G. Yang et al., "Effects of deposition temperature and annealing temperature on the morphology and electrochemical capacitance of $\mathrm{Ni}(\mathrm{OH}) 2$ thin films," J. Solid State Electrochem, vol. 16, no. 12, pp. 3761-3767, 2012, doi: 10.1007/s10008-012-1818-0. 
